lishment, the Intelligence Division is setting out to provide an information and project appraisal service. A start has been made, for example, in building up a centre of information in mineral processing, by assembling data from a wide variety of sources in such a way that they can be used in research and industry.

From what has been described it will be apparent that there is a wide choice of field before Warren Spring Laboratory, and that at the moment the main problem is that of selection, and of allocation of priorities. In addition to the factors which govern the work of other laboratories of the Department of Scientific and Industrial Research, there is the task of undertaking sponsored work to a greater extent, and on a larger scale. Such work may be carried out for Government departments or for industry, and it may be on a fully confidential basis. The special facilities of the Laboratory will also be available for use, in certain circumstances, by teams from industry, which can work in collaboration with the research staff of the Laboratory.

The programme is regularly considered by a Steering Committee, appointed by the Research Council, the present members of which are: Sir Harry Jephcott (chairman), Sir Harry Melville, Dr. R. Holroyd, Mr. D. A. Oliver and Mr. S. H. Clarke.

\title{
OBITUARIES
}

\section{Mr. T. L. Eckersley, F.R.S.}

THE death of T. L. Eckersley on February 15 removed another of the rapidly dwindling band of pioneers in the field of radio research, among whom he was notable both for his theoretical and practical work. His interest in electromagnetic waves was aroused while he was still at school at Bedales; but it was during the First World War, after studying at University College, London, and Trinity College, Cambridge, with some years at the National Physical Laboratory in between, that he made his first big contributions to radio-wave propagation. These were his explanation of 'night-effect' in direction-finding observed in Egypt and Salonika, in which he invoked the existence of an upper ionized layer giving rise to a reflected wave with variable polarization characteristics, and his observation of coastal refraction which he sought to account for in terms of the properties of Zenneck surface waves.

He was thus among the first to obtain evidence of the presence of the ionosphere by the reflexion of radio waves and so began a life-long interest in the magneto-ionic theory of propagation. His first work, however, on joining the Marconi Co. after the War was a classical research into the properties of earth screens for increasing the radiation efficiency of long. wave aerials, followed by his analysis of the results of observations made on very long-wave transmitters by $\mathrm{K}$. W. Tremellen and C. M. Allnutt during a round-the-world expedition. For more than twenty years Tremellen was Eckersley's personal assistant, and his patient observational work formed the basis of the succession of papers which Eckersley wrote on short-wave radio transmission.

The last of these was on scattering from 'clouds' in the ionosphere, a subject which has since become of great practical importance in the development of the ionospheric 'forward scatter' communication system. Not only did all this work lay the foundation of much of our knowledge of the part played by the ionosphere in long-distance propagation, but it also led to many advances in technique, for example, in the field of accurate direction-finding and in the measurement of field-strength and polarization characteristics.

Although he would not have claimed to be a pure mathematician, he had a consummate ability to apply mathematics to physical problems. Indeed, many of his experimental researches were preceded or sup- ported by elegant analysis. He had a great interest in modern physies, especially in its quantum and relativistic aspects, and it was the knowledge so acquired that inspired some of his finest work in radio. It was the phase integral treatment of potential barriers in atomic theory that led him to his brilliant applications to ionospheric and ground-wave propagation, while in the scattering of $\alpha$-particles he found an analogy for the scattering of radio waves as a function of wave-length, cloud size and scattering angle.

Eckersley had something of the absent-mindedness associated with genius, which was reflected in the style of his writing and made some of his papers difficult for others to read. He was thus not as well known in the world at large as he deserved to be; but in due course full recognition among scientists came with his election to fellowship of the Royal Society in 1938 and the award of the Faraday Medal of the Institution of Electrical Engineers in 1951. He was also a well-known figure at international radio conferences, especially at the C.C.I.R. and U.R.S.I. assemblies.

He was proud of the fact that he was a grandson of T. H. Huxley, and he was most happy in his family life, his wife being Eva, the daughter of Barry Pain, the Victorian novelist, who survives him with a son and two daughters. She is an able pianist and composer, and their home at Danbury, Essex, was often visited by distinguished musical friends. He was a delightful host, for he combined great courtesy with a delicate sense of humour, and though he did not play himself he had a great love of music.

At the time he died he had become almost completely helpless from multiple sclerosis, the first symptoms of which had appeared more than twenty years ago. In spite of increasing disability, he remained at work throughout the Second World War as scientific adviser to the Inter-Services Ionosphere Bureau at the Marconi Research Laboratories, and after his retirement in 1946 he continued to work at home for several more years.

During this period he published a number of papers, his devoted wife acting as his amanuensis. There is no doubt that it was her amazing courage and cheerfulness that maintained his life for so long, and indeed it was to pneumonia during the influenza epidemic that he finally succumbed. The loving care which surrounded him during those last years was a source of inspiration to all who witnessed it.

G. Mrllington 